\title{
SOBRE BRINQUEDOS E INFÂNCIA: ASPECTOS DA EXPERIÊNCIA E DA CULTURA DO BRINCAR
}

\author{
Danielle Barbosa Lins de Almeida*
}

RESUMO: Partindo do paradigma do pensador Walter Benjamin, um dos mais proeminentes do século XX, cujo materialismo evoca a categoria da infância desvinculada da ótica ideológica de uma visão complacente, este trabalho busca capturar o pensar sobre tal experiência por intermédio da leitura e da subseqüente discussão sobre textos de cerca de 80 anos, os quais surpreendem pela sua contemporaneidade. Assim, o presente trabalho inicia-se de uma reflexão crítica sobre a infância oriunda da leitura dos luminosos textos de Walter Benjamin sobre a cultura da criança. Ao revisitá-los, espera-se contribuir em direção à elucidação do grande enigma dos valores da infância, sendo esta fundamental à compreensão da modernidade.

Palavras-chave: Brinquedos. Infância. Criança. Adulto. Mimese. Representação. Experiência. Brincar.

ON TOYS AND CHILDHOOD:

ASPECTS OF THE EXPERIENCE AND CULTURE OF PLAYING

ABSTRACT: Based on the paradigm of philosopher Walter Benjamin, whose materialism evokes the category of childhood detached from an ideological and indulgent view, the present paper aims at capturing the experience of childhood through the reading and subsequent discussion of Walter Benjamin's surprisingly contemporary 80-year-old texts on children's culture. By revisiting such articles, It expects to further elucidate the enigma of childhood values as well as to provide a view on how such values help promote a more comprehensive account of modernity.

Key words: Toys. Childhood. Child. Adult. Mimesis. Representation. Experience. Playing.

* Doutoranda em Letras na Universidade Federal de Santa Catarina (UFSC) e professora adjunta do Departamento de Letras do Centro de Educação da Universidade Estadual da Paraíba (UEPB).E-mail: danielle_almeida@hotmail.com

Disponível em <http://www.cedes.unicamp.br> 
Sobre brinquedos e iInfância: aspectos da experiência e da cultura do brincar

\section{O brinquedo e a cultura lúdica do brincar}

$\mathcal{A}$

visão idealizada da infância como período livre das asperezas do mundo permite e justifica a necessidade de uma análise mais crítica e apurada sobre a infância na qualidade de categoria social.

$\mathrm{Na}$ realidade, estudar a experiência da infância e suas vicissitudes significa revisitar os conceitos de encolhimento e transitoriedade relacionados a um período que, segundo alguns autores (como, por exemplo, Hannah Arendt e o próprio Walter Benjamin), caracteriza-se pela ausência e incompletude. Dessa forma, trabalhar a compreensão de infância como categoria social requer essencialmente desvencilhar-se da noção linear do tempo para que se possa apreendê-la como elemento maior, submetido à constante lógica da reificação.

A cultura do brincar, ou, mais especificamente, o interesse pelos brinquedos como a materialização da atividade em si, teve sua origem na Alemanha, em lugares não especializados, como oficinas de entalhadores de madeiras ou de fundidores de estanho (Benjamin, 1984, p. 67). Foi somente a partir de meados do século XVIII que os brinquedos passaram a aflorar no competitivo mercado de fabricantes especializados. A partir desse período, as indústrias manufatureiras, que anteriormente tinham sua produção de brinquedos posta em segundo plano e eram restritas à fabricação apenas daquilo cujo ramo lhes competia, passaram a dividir entre si as tarefas distintas que culminariam na produção do brinquedo a ser vendido sob altos custos como mercadoria (idem, ibid., p. 68).

A fabricação especializada de brinquedos partiu efetivamente da necessidade de se produzir objetos de arte menores que pudessem ser utilizados na decoração interna das casas. Todavia, os brinquedos, inicialmente minúsculos, com o tempo ganharam tamanho e foram perdendo, por conseqüência, seu caráter "discreto, minúsculo e agradável" (Benjamin, 1984, p. 68). Concomitantemente, a indústria mundial dos brinquedos foi adquirindo espaço e atenção pela sua significativa e gradual inserção no contexto social.

$\mathrm{Na}$ paulatina passagem de um modelo artesanal de produção para um modelo industrial, o brinquedo deixou de ser um produto de "restos", cuja pluralidade de formas e materiais dava vazão ao subjetivo conteúdo imaginário da criança, para adquirir, então, um status de fabricação especializada, cuja representação poderia vir a predefinir ou sugerir a natureza da brincadeira. 
A capacidade da criança de escolher e adaptar objetos multiformes restos desprezados pelos adultos como "inúteis" e "inadaptados" -, com a finalidade de implementá-los em suas brincadeiras, segue como representação de sua fantasia e de sua auto-expressão. É o que Benjamin designa "fazer história a partir do lixo da história" (idem, ibid., p. 14). Neste sentido, para Benjamin, "quanto mais atraentes (no sentido corrente) forem os brinquedos, mais distantes estarão de seu valor como 'instrumentos de brincar'; quanto ilimitadamente a imitação anuncia-se neles, tanto mais se desviam da brincadeira viva" (idem, ibid., p. 70).

A íntima relação estabelecida entre o brinquedo e o brincar é pontuada por Arendt (1971), quando destaca a crença de outrora sobre o brincar como "o modo mais vívido e apropriado de comportamento da criança no mundo, por ser a única forma de atividade que brota espontaneamente de sua existência como criança”. Dentro dessa perspectiva, a ênfase no aprendizado por meio do brinquedo era total e só aquilo que podia ser aprendido mediante o referido objeto de brincar acreditava-se poder fazer justiça à vivacidade infantil (Arendt, 1971). Portanto, toda e qualquer atividade de aprendizado que forçasse a criança a uma atitude de passividade, praticamente "obrigava-a a abrir mão de sua própria iniciativa lúdica” (idem, ibid., p. 232).

Contudo, a crença de que um suposto preestabelecido conteúdo imaginário do brinquedo vem a determinar a brincadeira da criança é contestada por Benjamin, que a define como "equívoco fundamental" (1984, p. 69). Para ele, a relação dá-se na direção contrária, no momento em que é na brincadeira que a criança busca incluir o seu "brinquedo" ou "objeto de brincar": "a criança quer puxar alguma coisa e torna-se cavalo, quer brincar com areia e torna-se padeiro, quer esconder-se e torna-se ladrão ou guarda" (ibid., p. 70).

Com efeito, a "diluição" da criança no brinquedo possibilita-nos inferir que a natureza da relação entre o brinquedo e o brincar é quase simbiótica. O brinquedo, na qualidade de "estimulante material para fazer fluir o imaginário infantil", concretiza-se no "lúdico em ação", ou seja, na brincadeira em si (Kishimoto, 1997, p. 26). No momento em que a criança se mimetiza com o objeto, em absoluto tal objeto determina e delimita a sua infinita máscara imaginária infantil. Constituise, efetivamente, em um objeto híbrido e dialógico, o qual assume papéis dos mais diversos tipos, conforme a curiosidade e o interesse da 
Sobre brinquedos e iInfância: aspectos da experiência e da cultura do brincar

criança. Assume, portanto, aqui, seu maior valor simbólico como "instrumento de brincar" (Benjamin, 1984, p. 70).

A natureza multifacetária do brinquedo imprime-lhe um caráter mais que material: a simbologia deste instrumento de brincar atravessa a fronteira do físico em direção ao espiritual e faz dele instrumento que promove interação, diálogo, aproximação com o lúdico, reforço de habilidades cognitivas e de relação de sociabilidade. A ação lúdica concebida na justaposição entre brinquedo e brincadeira apresenta, todavia, significados contraditórios: se vista como atividade livre ou supervisionada pelo adulto, a brincadeira submete o brinquedo à função de suporte para a criatividade ou para o controlado ensino de conteúdos escolares.

Essa polissemia de significados atualizada na relação íntima estabelecida entre a criança e seu objeto de brincar é reforçada por Kishimoto (1997), que enfatiza a ausência de um sistema de regras que organize a utilização do objeto de brincar na brincadeira. Isso é o que torna possível a diferenciação da estrutura do brinquedo daquela do jogo na brincadeira da criança. Os brinquedos lidam com o âmbito da reprodução da realidade da criança e seus contextos e podem, ou não, incorporar representaçôes de um universo à parte: aquele presente nas histórias em quadrinhos, em seriados de TV e no mundo encantado de contos de fada. Em suma, a tese central de Kishimoto (1997) é que o brinquedo, em sua forma e dimensão delicadas e antropomórficas, "metamorfoseia e fotografa [os diversos tipos de realidades], não reproduzindo apenas objetos, mas uma totalidade social" (p. 24).

O que Benjamin denomina "falsa simplicidade dos brinquedos modernos" (1984, p. 69) confirma parcialmente a generalizada subestimação do valor semântico dos referidos objetos. Os brinquedos têm freqüentemente o seu significado social negligenciado na medida em que a qualidade a eles atribuída os remete à mera categoria de objetos de entretenimento das crianças, ou até mesmo, como Brougère menciona, como "objeto[s] concebido[s] exteriormente ao ato de brincar" (1998, p. 20). A dimensão existencial dos brinquedos, todavia, vai mais além. Sua função não se limita a construções de materiais e formas múltiplas e heterogêneas. Representam, em si, categorias sociais próprias e subjetivas cujas dimensões superam o material, cultural ou técnico. Por meio de suas representações veiculadas pela rememorização, remetem o adulto ao seu tempo de infância, o qual, acometido pela lembrança do brincar, percebe a origem do seu gestual cotidiano. Neste sentido, Ben- 
jamin pontua que os nossos hábitos consistem em "formas petrificadas e irreconhecíveis da nossa primeira felicidade, de nosso primeiro terror (...)" (1984, p. 75).

O fascínio de Benjamin pelo brincar é fruto de sua percepção de que a essência da brincadeira reside na inovação do "fazer de novo". O jogo, segundo ele, não mais é senão um hábito; "comer, dormir, vestirse, lavar-se devem ser inculcados no pequeno irrequieto através de brincadeiras, que são acompanhadas pelo ritmo dos versinhos" (ibid.). Assim prossegue: "Todo hábito entra na vida como brincadeira, e mesmo em suas formas mais enrijecidas sobrevive um restinho de jogo até o final" (ibid.).

$\mathrm{Na}$ esteira do que propõe o filósofo norte-americano George Herbert Mead (1934, apud Pinto \& Sarmento, 1997, p. 42), fundador do interacionismo simbólico, o brincar - ou "faz-de-conta" - "constitui um passo essencial no processo de autoconsciência da criança" (ibid.), uma vez que deste processo decorrem duas conseqüências decisivas para o desenvolvimento infantil: (1) a experiência da alteridade, relativa ao mundo exterior, que se dá anteriormente à experiência que as crianças fazem de si, e (2) a experiência de si mesma - ou de self-, em que "ao fazer a experiência do outro, a criança vê-se a si mesma, [e] objetiva-se como realidade separada do mundo" (ibid., p. 42-43).

A primeira expressão mimético-sensorial do brincar dá-se inicialmente no próprio corpo da criança, o qual constitui seu primeiro brinquedo. As múltiplas possibilidades oferecidas pelo primeiro "instrumento de brincar" (do alemão Spielzeug) da criança transformam o corpo em um elemento que, misturado ao meio, realiza e aproxima a experiência subjetiva do brincar de sua experiência social plena.

De fato, a experiência social da criança atualizada na brincadeira e no jogo encontra-se permeada por condutas miméticas no momento que possibilita a essa criança ir além de sua capacidade de produzir similitudes para lançar-se à transmutação entre os diversos e possíveis papéis sociais, pelos quais ela transita livremente: entre o ser comerciante ou ser professor, ou entre o personificar-se de moinho de vento ou de trem (Benjamin, 1985, p. 108).

A capacidade mimética, fundamentada no conceito de mimese, caracteriza-se pela faculdade de reconhecer e reproduzir semelhanças, distinguindo-se da imitação por não se tratar propriamente de uma 
Sobre brinquedos e iInfância: aspectos da experiência e da cultura do brincar

replicação e, sim, de uma forma de representação ou de re-elaboração. Segundo Benjamin, para se compreender o comportamento mimético e se avaliar seu significado, "não basta pensar no sentido contemporâneo do conceito de semelhança" (idem, ibid.). É preciso significar o comportamento mimético por meio de seu sentido filogenético, no qual as semelhanças percebidas em nível consciente nos nossos rituais cotidianos só de fato "assumem sua significação decisiva quando levamos em conta que fundamentalmente todas elas estimulam e despertam a faculdade mimética que lhes corresponde no homem" (idem, ibid., p. 109).

O conceito de mimese envolve, em última análise, a diluição de si para fins de aproximação com o outro. Por este motivo, a brincadeira torna-se um ritual mimético no momento em que a criança consegue diluir-se no espaço, no lugar e no tempo para dar significado ao objeto que manipula ou aos inúmeros papéis que representa com relativa tranqüilidade nas diversas vezes que brinca.

Ambas as dimensões sociais e afetivas acerca do brinquedo como objeto de suporte da brincadeira têm uma relação estreita com a compreensão de infância, embora seja argumentado que são insuficientemente exploradas e valorizadas (Pinto \& Sarmento, 1997, p. 43). Por este motivo, buscarei tratar, na seção a seguir, da experiência social da infância sob uma perspectiva mais ampla, privilegiando uma abordagem contemporânea da infância como construção social.

\section{A experiência da infância}

A (in)visibilidade da infância na sociedade adulta contemporânea aponta para a complexa natureza de sua condição social. Incapaz de agir por si própria em um mundo cercado por perigos dos mais diversos, à criança é vetada uma participação social efetiva sob o argumento de que necessita de proteção, o que evidencia um pensamento puramente paternalista, em face da velha teoria que concebe as crianças como "homúnculos", ou seres humanos em miniatura, desprovidos de especificidade própria e originalidade.

Tal teoria retira das crianças o "estatuto de atores sociais" para destinar-lhes a exclusiva função de "destinatários das medidas protetoras dos adultos", os quais são tidos como "inerentemente sábios, racionais e maduros" (Pinto \& Sarmento, 1997, p. 20). Com respeito a isso, 
o próprio Benjamin contenda que "demorou muito tempo até que se desse conta de que as crianças não são homens ou mulheres de dimensões reduzidas" (1984, p. 64).

Em contrapartida, embora designe a referida abordagem como um dos maiores erros em toda a educação passada, Arendt (1971) toma alguns dos pressupostos básicos da relação entre crianças e adultos como possíveis fatores fomentadores da crise educacional atravessada pela América. Um dos pressupostos de Arendt estaria fundado na tentativa contemporânea de se "igualar ou apagar as diferenças entre jovens e velhos (...), crianças e adultos (...)" (p. 229) a fim de conceder-lhes autoridade suficiente para que governem seu próprio universo. Tal liberdade, contudo, somente pode ser conquistada à custa da autoridade do mais velho, o que, segundo Arendt (1971, p. 230), vem acarretar "uma situação em que $o$ adulto se acha impotente ante a criança individual e sem contato com ela" (idem, ibid.).

No quesito autoridade, pode-se, a partir daí, questionar a real utilidade de uma possível emancipação das crianças da autoridade dos adultos, tendo em vista que um grupo de crianças tem absoluta supremacia sobre um adulto isolado. Tal situação, afirma Arendt, torna-se por definição "irremediável" e remete à tirania, na medida em que, por terem sido barradas do mundo dos adultos sob o argumento de terem a sua independência respeitada, as crianças são mantidas "artificialmente em seu próprio mundo" (idem, ibid., p. 233), privadas de qualquer iniciativa de argumentação ou contestação, restando-lhes apenas o caminho da delinqüência ou do conformismo.

Em suma, sob o rótulo de "autonomia do mundo da infância", afasta-se e exclui-se as crianças do mundo dos adultos, privando-lhes de um relacionamento baseado no aprendizado contínuo, no qual a infância se destaca como etapa central do ser humano em preparação para a vida adulta, caracterizando, assim, o nicho vital da tese de Arendt (idem, ibid.).

Paradoxalmente, a chamada "educação moderna", embora almeje um "mundo de crianças", extingue, segundo Arendt, as condiçōes devidas ao seu desenvolvimento e crescimento, em não levar "suficientemente em consideração a natureza íntima da criança e suas necessidades" (ibid., p. 237). O pseudo "Século da Criança" contraditoriamente negligencia suas mais elementares condiçôes de vida, atribuindo à escola a responsabilidade singular e coletiva de introduzir a criança em um 
Sobre brinquedos e iInfância: aspectos da experiência e da cultura do brincar

mundo dirigido por adultos. O educador torna-se, dessa maneira, como Arendt contenda, "um representante de todos os habitantes adultos", assumindo, portanto, a responsabilidade pelo mundo do qual faz parte, "apontando (seus) detalhes e dizendo à criança - Isso é o nosso mundo" (Arendt, 1971, p. 239).

$\mathrm{Na}$ clara recusa de assumir a responsabilidade pelo mundo que compõe, o adulto reforça uma situação de "perda geral de autoridade" (idem, ibid., p. 241), na qual ele se afasta de seu papel de verdadeiramente instruir as crianças na "arte de viver", reforçando ainda mais a muralha que separa o "mundo das crianças" da comunidade adulta.

É na realidade impossível, menciona Arendt, se estabelecer uma linha "limítrofe" entre a infância e a condição adulta, tendo em vista que ambas as experiências vêm a atuar em um processo contínuo caracterizado essencialmente por sua natureza complementar.

Tradicionalmente, as ações de experiência e vivência de crianças e jovens tendem a ser desvalorizadas se comparadas com aquelas atribuídas aos adultos. Com efeito, conforme Benjamin salienta, com ares de superioridade os adultos costumam subestimar os anos de juventude, não percebendo, contudo, que crianças e jovens se servem de outros valores os quais não se prestam, necessariamente, à experiência (1913, p. 24). Assim, Benjamin complementa:

A máscara do adulto chama-se "experiência" (...) ele sorri com ares de superioridade (...) de antemão ele já desvaloriza os anos que vivemos, converte-os em época de doces devaneios pueris, em enlevação infantil que precede a longa sobriedade da vida séria. (1984, p. 23)

A assertiva de Benjamin vem a comprovar que à própria juventude é desmerecida a qualidade de "experiência", cujos anos, afirma ele, são comparados com uma "curta noite", esta sim a preceder a chamada experiência em si, a ser refletida em "anos de compromisso, pobreza de idéias e monotonia" (idem, ibid.), valores estes associados à vida adulta.

A desconsideração do estatuto das crianças como verdadeiros atores sociais de seus contextos conduz à criação do estudo das chamadas "culturas de infância" cujo universo é extremamente permeável e não alheio à "reflexibilidade global" (Pinto \& Sarmento, 1997, p. 22). Busca-se nele apreender o conhecimento específico do mundo alternativo ao dos adultos, e o saber de sua natureza, como fruto de uma possível ação social se epistemologicamente sustentado (idem, ibid.). 
A noção de infância é moderna, começando a "adquirir pertinência (...) a partir dos finais do século XVII e especialmente do século XVIII" (Ariès, 1960, apud Pinto \& Sarmento, 1997, p. 34). Tendo em vista que antes disso as crianças não eram reconhecidas como sujeitos com especificidade própria, sendo estas tratadas e representadas como adultos em miniatura, uma vez que trabalhavam, comiam, divertiam-se e dormiam em meio aos adultos, é possível estabelecer uma curiosa analogia com as diversas crianças de contextos periféricos de nossos dias.

Com o advento da industrialização e a procura de mão-de-obra infantil, a nossa criança contemporânea retorna, então, ao seu antigo status de "adulto em miniatura", condição que não lhe confere qualquer sentimento de infância e trata de incorporá-la no contexto social adulto tão logo adquira capacidade de viver sem a efetiva solicitude de seus pais e obtenha "um certo grau de discernimento de si e do mundo" (Pinto \& Sarmento, 1997, p. 35). Analogamente, a criança de nossos dias compartilha com o adulto a divisão do trabalho braçal, a carga horária pesada do trabalho no comércio informal, o gerenciamento do lar em ocasião da ausência dos pais, o convívio em ambientes de adultos. Precocemente, vê-se, então, essa criança acometida por uma responsabilidade adulta que a obriga a abreviar ou encolher seus anos de infância para assumir o seu papel efetivo perante a sociedade que compóe.

Um outro ângulo para se visualizar o processo histórico de construção da noção moderna de infância em sua totalidade passa pela compreensão de um "simétrico processo de construção da noção de adultez" (Pinto, 1997, p. 55). Fala-se, portanto, em uma nova cultura que desvaloriza a adultez e cultiva o ser criança, à luz da discussão acerca da "infantilização generalizada da sociedade" (idem, ibid., p. 57).

$\mathrm{O}$ tratamento concedido à experiência da infância pela sociedade adulta contemporânea pode ser caracterizado como paradoxal. Ao mesmo tempo que acaricia os estágios iniciais da infância, renega um tratamento infantilizado às crianças em estágios posteriores, fazendo-se valer do adjetivo "infantil" para desqualificar ações e comportamentos de ordem imprópria. Isso pode ser verificado em Calvert quando aponta:

Espera-se delas [das crianças] que se comportem como crianças mas são criticadas em suas infantilidades; é suposto que brinquem absorvidamente quando se lhes diz para brincar, mas não se compreende por que não pensam em parar de brincar quando se lhes diz para parar; espera-se que sejam 
Sobre brinquedos e iInfância: aspectos da experiência e da cultura do brincar

dependentes quando os adultos preferem a dependência, mas deseja-se que tenham um comportamento autônomo; deseja-se que pensem por si próprias, mas são criticadas pelas suas "soluções" inteligentes. (apud Pinto \& Sarmento, 1997, p. 13)

O fenômeno de mudança que caracteriza a abrupta passagem de uma situação de "reinado absoluto" das crianças para uma outra em que "passou a ser olhada e sentida como uma realidade incômoda" (Ariès, apud Pinto \& Sarmento, 1997, p. 50) conduz à discussão acerca das contradições entre o discurso social e político sobre a infância e as práticas sociais relacionadas às crianças. Nesse contexto, Pinto \& Sarmento (1997) apontam para o que eles chamam de "paradoxos da infância", definidos como sendo o "caráter paradoxal" com o qual as crianças são tratadas pela sociedade adulta. Segundo os autores, as chamadas inconsistências da "agenda política da infância" (Sgritta, apud Pinto \& Sarmento, 1997, p. 12) vêm atestar o valor que lhe é concedido, valor este que acaba por gerar efeitos contraditórios com relação àqueles propostos na ordem do discurso e das políticas sociais. Um dos fatores que fomentam tal assertiva é que só agora, quando as crianças representam um menor número relativo no conjunto da população, a sociedade dispóe-se a estudar a sua existência de forma efetiva (Pinto \& Sarmento, 1997, p. 12).

Além disso, a própria natureza da infância inicia-se na compreensão da acepção da palavra "infância". Como delimitar seus limites etários? Como definir os direitos das crianças? Em que paradigmas, correntes teóricas e/ou metodológicas apoiar-se para debater a questão das culturas das crianças e os fatores de heterogeneidade destas?

Tais questôes permanecem ainda por serem elucidadas e discutidas. Por ora, resta-nos desafiar a hegemonia do discurso público acerca das crianças - seja este expresso na forma de linguagem corrente ou de estatuto social - para daí partirmos em busca de um significativo progresso na condição de vida das crianças dentro do contexto social.

\section{Considerações finais}

Ao verificar-se uma equivocada abordagem sociológica do mundo da criança e da infância, que a concebe como categoria uniforme, universal e homogênea, torna-se imprescindível propor a sua desconstrução e subseqüente reconstrução com base em conceitos de heterogeneidade e autonomia. Ao perceber-se na criança o verdadeiro ator soci- 
al de suas ações, um ser ativo dotado de sentido de competência na sociedade em que vive, espera-se construir um novo sentido de valorização da experiência da infância, longe da visão idealizada do adulto que, ao olhar para trás, contempla sua própria infância.

Recebido em novembro de 2005 e aprovado em janeiro de 2006.

Referências bibliográficas

ARENDT, H. A crise na educação. In: ARENDT, H. Entre o passado e o futuro. São Paulo: Perspectiva, 1971. p. 221-247.

BENJAMIN, W. Reflexões: a criança, o brinquedo e a educação. São Paulo: Summus, 1984.

BENJAMIN, W. A doutrina das semelhanças. In: Benjamin, W. Magia e técnica, arte e política. São Paulo: Brasiliense, 1985. p. 108-113. (Obras escolhidas, v. 1)

BENJAMIN, W. Infância em Berlim por volta de 1900. In: BeNJAMIN, W. Rua de mão única. São Paulo: Brasiliense, 1987. p. 71-142. (Obras escolhidas, v. 2)

BROUGÈRE, G. A criança e a cultura lúdica. In: BrougÈre, G. O brincar e suas teorias. São Paulo: Pioneira, 1998. p. 19-32.

KISHIMOTO, T. Brinquedo e brincadeira: usos e significações dentro de contextos culturais. In: Santos, S.M.P. (Org.). Brinquedoteca: o lúdico em diferentes contextos. Petrópolis: Vozes, 1998. p. 23-40.

KISHIMOTO, T. Jogo, brinquedo, brincadeira e educação. São Paulo: Cortez, 1997.

PINTO, M. A infância como construção social. In: Pinto, M.; SARMENTO, M.J. As crianças: contextos e identidades. Braga: Centro de Estudos da Criança, Universidade do Minho, 1997. p. 33-73.

PINTO, M.; SARMENTO, M.J. As crianças e a infância: definindo conceitos, delimitando o campo. In: Pinto, M.; Sarmento, M.J. As crianças: contextos e identidades. Braga: Centro de Estudos da Criança, Universidade do Minho, 1997. p. 9-30. 